\title{
Acquisition pattern analyses for recognising cross-sell opportunities in the financial services sector
}

\author{
RECEIVED: 23 OCTOBER, 2000
}

Leonard Paas and Ton Kuijlen

C. Anthoniszstraat 64-I, I07I VX Amsterdam. The Netherlands.

Tel: +3। 20584 6266; Fax: +3। 20584 62I2; e-mail: paas@dds.nl

\begin{abstract}
In previously published papers it was shown that consumers often acquire financial products in the same order. Knowledge on such acquisition patterns is useful for marketing purposes. This study aims to define optimal utilisation of the acquisition pattern approach for cross-sell purposes. The proposed approach borrows a psychometric tool, the Mokken scale analysis, to investigate acquisition patterns. The sequential logit decision model is used to establish which clients found at a certain step in an acquisition pattern are most likely to acquire the next product found in such an order. The study focuses on this particular application of the sequential logit decision model.
\end{abstract}

\section{INTRODUCTION}

In 1982 Felvey $^{1}$ pointed out that existing clients are better prospects for a company's products than consumers having no relationship with the firm. This proposition regarding cross-sell is still relevant for contemporary marketing. Moreover, cross-sell can also supplement conventional prospect selection approaches, which have be- come less effective in recent years. The conventional method of prospect selection is defined here as making a product offer, via direct mail, call centres or any other channel of communication. This offer is made to a random selection of clients. Then a model is built through comparing, in one way or another, the characteristics of clients who responded, with characteristics of clients who did not react positively to the offer made. Then all clients possessing characteristics of respondents are selected for the main campaign. The problem for contemporary marketing is that the number of sales made through direct marketing campaigns, relying on this form of prospect selection, has strongly decreased over the last decade., ${ }^{2,3}$

It is proposed that cross-sell offers an alternative means of prospect selection. To implement effective cross-sell strategies marketers require information on the order in which clients acquire products and characteristics of clients who are potential buyers of specific products in such orders. With regard to the first point, previous research shows consumers acquire

\section{Leonard Paas}

works as a

consultant at the

Da Vinci Group

(The Netherlands).

$\mathrm{He}$ is engaged in

data mining,

predictive

modelling,

controlling data

quality, customer

segmentation and

credit scoring.

Leonard is also

working on a

doctoral thesis.

Ton Kuijlen is

head of the R\&D

department of the

Database

Marketing Centre at the Postbank

(The Netherlands) and a professor of statistical methods at Tilburg

University. 
financial products in highly similar orders, called acquisition patterns. Acquisition patterns are relevant for cross-sell, because current product ownership can indicate which product should be offered next to specific clients. Or as Paroush ${ }^{4}$ eloquently put it over three decades ago:

'If the order of acquisition is commodity A, B and C, it pays the producer of commodity $\mathrm{B}$ to send salespersons to consumers owning only commodity A, or, if a discount is offered on commodity $\mathrm{A}$, it is better to make it conditional on the purchase of $\mathrm{B}$ than on the purchase of C (commodities which are closer in the order of acquisition may be considered more complementary).'

Methods for investigating acquisition patterns have already been studied extensively. ${ }^{5-7}$ The second condition mentioned above, effectively defining which clients are prospects for specific products in an acquisition pattern, has, however, been studied less systematically. Previous studies concentrated on techniques for investigating coherence between the total number of acquired products from a specific acquisition pattern and different consumer characteristic. $^{8-10}$ This approach is less suitable for recognising cross-sell opportunities, because factors playing a role in one particular stage of an acquisition pattern may take on a different role in another stage or may even be completely irrelevant. For instance, in Paroush's hypothetical ex- ample risk averse clients owning only product $A$ could be more inclined to acquire product $B$ than other owners of product A. In the next step, however, $\mathrm{B}$ to $\mathrm{C}$, risk aversion could play no role whatsoever. It is therefore proposed that a model should take note of client characteristics relevant for each specific stage in an acquisition pattern.

Up-to-date and suitable techniques for supporting such analyses have not been presented. An existing statistical technique, the Sequential Logit Decision Model (SLD Model) ${ }^{11,12}$ is used for this purpose below. The SLD model is applied to a representative selection of clients found in the marketing database of a large financial services provider in The Netherlands. Such transactional data are analysed because in most practical situations marketing analysts also rely solely on such data. The latter point is discussed further in the next section of the paper. In the next section some theoretical issues relevant for the proposed application of the SLD model are also discussed, then the analysed data are introduced. The data set consists of 6,490 subjects, it was collected in 1997 and contains indications on ownership of the following financial products: current account, savings accounts, investment trusts and securities. It will be seen below that most subjects acquire these products in the same order. This is not the main topic of the current study; the focus is on the application of the SLD model for recognising consumer 
characteristics influencing product acquisitions in the found acquisition pattern.

\section{THEORETICAL ISSUES}

Some theoretical issues are addressed before presenting the empirical investigations. First, the suitability of transactional data for investigating acquisition patterns is evaluated. Then how the acquisition pattern approach can be applied to transactional data for the purpose of enhancing cross-selling is discussed.

As mentioned above, marketers usually conduct analyses for marketing campaigns on transactional data found in a company's marketing database. Sometimes a company also interviews their clients to deduce relevant information for marketing purposes. Larger financial services providers with millions of clients are not, however, inclined to interview all their customers. Thus, in most practical situations marketers can only use information deduced through the analyses of transactional data.

Transactional data have both advantages and disadvantages. A strong point is that this type of data represents actual behaviour. A record of actual behaviour may be considered more valid than indications given in a survey, which may be unreliable due to poor memory of respondents, refusal to divulge information etc. ${ }^{13} \mathrm{~A}$ drawback of transactional data is that only behaviour displayed at a single company is stored. No information is available on ownership of financial products from other companies.

For the purposes of this paper, however, this drawback is less relevant, as acquisition of a product at company $\mathrm{X}$ implies the buyer has a need for the product and this subject chose to acquire the product at company $\mathrm{X}$. Of course, both conditions need to be fulfilled if a consumer is to acquire a specific product at company $\mathrm{X}$. Relevance of the second condition implies that survey data, containing general information on ownership of products at different financial services providers, are less useful when predicting the next product a subject may acquire at company X. For example, if survey data indicate that the next product a consumer could acquire is a savings account, then it is possible that this individual does not want to acquire this product at company $\mathrm{X}$.

After these remarks on transactional data, the main theme of the discussion is picked up again. In this context it is proposed that acquisition pattern analyses for recognising cross-sell opportunities, consists of two steps. First, the analyst should investigate the order in which products are usually acquired. Mokken scale analysis ${ }^{14}$ is a suitable tool for this purpose. That is to say, if ownership patterns fulfil the assumptions of the Mokken scale model, then products should be placed in the same acquisition pattern and the order in which most consumers acquire the products incorporated in the set is described through the order of ownership levels. Products owned by a larger 
proportion of consumers usually being acquired before products owned by fewer subjects.

Mokken scale analysis utilises crosssectional data to support such analysis. The following remarks by Feick ${ }^{15}$ give a brief description on the basics of this particular application of Mokken scaling:

'If there is a hierarchical pattern of behaviour, researchers should observe only behaviours consistent with this single pattern. That is, if the hierarchy is that $\mathrm{A}$ is acquired before $\mathrm{B}$ and $\mathrm{B}$ before $\mathrm{C}$, we should find few instances of acquisition of $\mathrm{C}$ without $\mathrm{A}$ and $\mathrm{B}$, and so on.'

The order in which products are acquired reflects priorities regarding the satisfaction of different needs that consumers have. Products with utilities relevant for the satisfaction of more basic needs are usually acquired before products for satisfying higher order needs. ${ }^{16}$ This application of the Mokken scale analyses will not be elaborated on as it has been previously addressed. ${ }^{17}$

As mentioned above, the focus is on utilising the Sequential Logit Decision Model (SLD model) for deducing information from acquisition patterns which is relevant for cross-sell purposes. This utilisation of the SLD model is described through an example. Consider an acquisition pattern with the following products: current account, credit cards and loans. Application of the SLD model implies that three logit models have to be built. The first model aims to distinguish owners of the first product in the acquisition pattern (the current account) from all other consumers. The second model is built on data representing behaviour of current account owners; subjects who do not own this product are excluded from this analysis. The analysis relevant for this particular step aims to recognise owners of the current accounts who are relatively likely to have taken a second step in the acquisition pattern (acquiring the credit card). Last of all, the third step of analysis aims to recognise creditcard owners who also possess a loan. Thus, this approach investigates which types of consumers found at a specific step in an acquisition pattern are more likely to have acquired the next product in this order.

An important assumption in the approach is that subjects who do not own a product but who do possess the characteristics of owners of the product of interest are considered prospects. For example, current account owners who do not own a credit card but do happen to possess the characteristics of creditcard owners are considered prospects for the credit card. This assumption has already been proposed and validated in the propensity score approach. ${ }^{18}$

Despite the potential use of the proposed application of the SLD model some limitations require mentioning. First, skipping behaviour in the acquisition pattern is not modelled. In the example discussed above, clients owning only a current account may 
Figure 1: Found acquisition pattern

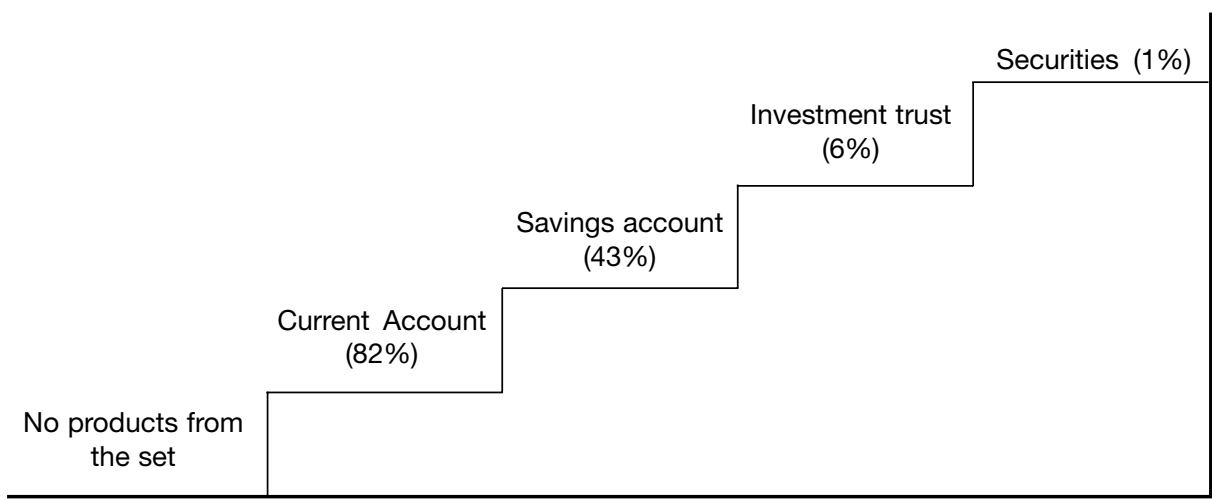

skip the credit card and acquire a loan. In the empirical section of this paper, it will be seen, however, that only a small minority of subjects displays such skipping behaviour. Therefore, the most commonly displayed behaviour is modelled through the proposed approach. Another limitation is that a client, who is considered a prospect for a product, may have acquired this product from a competitor. This is not, however, a result of the approach but of using transactional data and therefore applies for most utilised prospect selection techniques. Use of external data could deal with this problem, but, as mentioned above, this can mean that rather large numbers of clients need to be interviewed.

\section{DATA AND FOUND ACQUISITION PATTERN}

The analysed data set consists of a representative selection of 6,490 subjects from a marketing database of a large Dutch financial services provider (company X). Ownership indications of the following four products are available: current accounts, savings accounts, investment trusts and securities. These products form a Mokken scale according to the criteria described by, for example, Mokken and Lewis. ${ }^{19}$ As discussed above, fit of the Mokken scale model to product ownership patterns implies that products with higher ownership levels are usually acquired before less commonly owned products. For the product set here it is therefore proposed that the acquisition order presented in Figure 1, ie most consumers first acquire the current account, then the savings account, the investment trust and, finally, securities. Percentages of subjects owning each product at company $\mathrm{X}$ are also shown in Figure 1.

The dates at which each client acquired various products are also stored in the transactional databases of company $\mathrm{X}$. These dates were used to 
Table 1

\section{RELEVANT VARIABLES}

$\begin{array}{ll}\text { Abbreviation } & \text { Description } \\ \text { Income_Transfer } & \begin{array}{l}\text { Indication whether the subject receives income on one of the } \\ \text { accounts of the financial services provider }\end{array} \\ \text { Income_Amount } & \begin{array}{l}\text { Amount of income received on all accounts } \\ \text { Years_Client }\end{array} \\ \text { Age } & \begin{array}{l}\text { Agmber of years that the subject has been a client at company X } \\ \text { Agears }\end{array}\end{array}$

verify the found acquisition pattern. Analyses show that 95 per cent of the clients owning both the current account and the savings account indeed acquired the current account first. Furthermore, 83 per cent of the subjects owning both the savings account and an investment trust acquired the savings account first and 86 per cent of the subjects owning both investment trusts and securities acquired an investment trust before becoming owners of securities. This consistency implies that analysts who only have access to ownership indications of products can investigate acquisition patterns using the Mokken scale analysis.

As for the data used to build the SLD model, Table 1 displays variables used to distinguish subjects who have taken a next step in an acquisition pattern from other clients. Below, abbreviated names of variables are used. Note that two variables relevant for income are included in Table 1. The variable 'Income_Amount' des- cribes the monthly income that is transferred to company $\mathrm{X}$ accounts. If subjects transfer no income whatsoever, implying that information concerning income of the subjects is missing, this variable takes on the value ' 0 '. The other variable regarding income, 'Income_Transfer', also takes on the value ' 0 ' when no income is transferred to company X. However, Income_Transfer equals ' 1 ' if the subject does transfer income to a company $\mathrm{X}$ account (note if income is transferred to company $\mathrm{X}$ Income_Amount does not take on the value 1 , but reflects the amount of transferred income). Such use of dummy variables is an effective way of dealing with missing values. Moreover, found effects can also be meaningful from a theoretical perspective. For example, if only Income_Transfer has a significant positive effect, then the transfer of income is the only point that matters, with regard to the effects of income. If, however, both 
Table 2

\section{FOUND LOGISTIC REGRESSION MODELS}

\begin{tabular}{lllll}
\hline & $\begin{array}{l}\text { Step 1: } \\
\text { Nothing } \rightarrow \text { CA }\end{array}$ & $\begin{array}{l}\text { Step 2: } \\
\mathrm{CA} \rightarrow \mathrm{SA}\end{array}$ & $\begin{array}{l}\text { Step 3: } \\
\mathrm{SA} \rightarrow \mathrm{IT}\end{array}$ & $\begin{array}{l}\text { Step 4: } \\
\text { IT } \rightarrow \mathrm{S}\end{array}$ \\
& & & & \\
Effect & $1.8458^{\star \star}$ & $-0.8804 \star \star$ & $2.7355^{\star \star}$ & $-0.6108^{\star \star}$ \\
Constant & $1.7475^{\star \star}$ & $0.3927 \star \star$ & $-0.3861^{\star}$ & \\
Income_Transfer & $0.0007 \star \star$ & $0.0001 \star \star$ & $0.0002^{\star \star}$ & \\
Income_Amount & & $0.0280^{\star \star}$ & $0.0207 \star \star$ & $-0.0112^{\star}$ \\
Years_Client & & & & \\
Age & & & & \\
Quality measure & & & & \\
Model fit & $\mathrm{df}=7 ;$ & $\mathrm{df}=8 ;$ & $\mathrm{df}=8 ;$ & $\mathrm{df}=1 ;$ \\
& $\chi^{2}=3.37 ;$ & $\chi^{2}=91.44 ;$ & $\chi^{2}=5.36 ;$ & $\chi^{2}=5.52 ;$ \\
High score group & $\mathrm{p}<0.85$ & $\mathrm{p}<0.00$ & $\mathrm{p}<0.72$ & $\mathrm{p}<0.02$ \\
Low score group & $59.3 \%$ & $62.5 \%$ & $17.4 \%$ & $27.5 \%$ \\
& $57.4 \%$ & $36.4 \%$ & $7.5 \%$ & $22.6 \%$ \\
\hline
\end{tabular}

Income_Transfer and Income_Amount give significant positive effects, then the amount of income transferred is also relevant, in a particular step of the acquisition pattern.

\section{FOUND SLD MODEL}

In order to build the SLD model four logit analyses were run, one for each step in the acquisition pattern presented in Figure 1. These analyses were conducted using SPSS. Only significant effects were maintained in the final models; non-significant effects were discarded in a stepwise manner, the effect with the largest probability of resulting from chance being discarded first. This approach is similar to backward stepwise regression.

The significant parameters in the SLD-model are presented in Table 2. If a single star follows a parameter, then the effect is significant at the 5 per cent level, ie the probability that the effect is a result of chance is smaller than 5 per cent. Two stars imply significance at the 1 per cent level. Note that magnitude is not an effective indication for the strength of the effect, because the number of values each variable can take on differs. For example, the variable Income_Transfer can take on one of two possible values; 
a subject either does or does not transfer income to a company $\mathrm{X}$ account. The effect of age is scaled on an increase of one year, thus, for a 30-year difference the effect displayed in Table 2 is multiplied by 30 . To enhance interpretation only directions of found effects are discussed.

Table 2 also displays some figures concerning the quality of each model. First, model fit is tested through maximum likelihood estimation. If the probability that deviations between model predictions and actual patterns found in the data can be attributed to chance is smaller than 5 per cent, then the model does not fit the data. The analyses, however, are conducted on a database containing a large number of subjects. This means minor deviations from model predictions can result in significance of the maximum likelihood test. ${ }^{20}$ Therefore, another measure for model quality is reported: ie extent to which a cut-off point can distinguish clients who have taken the next step in an acquisition pattern from other individuals. In Table 2 the following abbreviations are used: $\mathrm{CA}=$ Current Account; $\mathrm{SA}=$ Savings Account; $\mathrm{IT}=$ Invest ment Trust; $\mathrm{S}=$ Securities.

The implications of Table 2 are illustrated through discussing the model relevant for the second step in the acquisition pattern (CA $\rightarrow$ SA). The reported effects show that owners of a current account at company $\mathrm{X}$ who have their income transferred to company $\mathrm{X}$ relatively often own a savings account (the effect of
Income_Transfer is positive). Furthermore, as the amount of transferred income is greater, the probability that the client owns a savings account is also greater. The latter is displayed in Table 2 by the positive effect of Income_Amount. The positive effect of Years_Client reveals that current account owners who have been clients at company $\mathrm{X}$ for a longer period also have a greater probability of owning a savings account.

Concerning model quality, maximum likelihood estimation shows that the model aimed at explaining which types of current account owners have also acquired a savings account does not fit the data, ie df $=8 ; \chi^{2}=91.44$; $\mathrm{p}<0.00$. The second quality index, however, shows something different (this implies that the poor fit is probably due to the large number of subjects in the data set). For the purpose of interpreting this second test it is assumed that owners of a current account are divided in two groups of equal size. Current account owners with characteristics implying a small probability of savings account ownership, according to the model in Table 2 , are allocated to the low score group. Subjects with a high probability are placed in the high score group. Table 2 shows that subjects in the high score group have a 62.5 per cent probability of owning a savings account. Ownership of the savings account is substantially lower in the low score group, ie 36.4 per cent. Thus, the 37.5 per cent of the subjects in the high score group who have not acquired the 
savings account to date, are considered prospects for this product. As mentioned above, this assumption is consistent with the assumptions of the propensity score approach.

The models for the other steps may be interpreted in a similar manner. For sake of brevity each specific model is not discussed, the reader is referred to Table 2 for more information. The most relevant point, is that some variables have different effects in various steps of the acquisition pattern. For example, Income_Transfer has a positive effect in the first two steps (no products $\rightarrow$ CA and CA $\rightarrow$ SA). In the third step $(\mathrm{SA} \rightarrow \mathrm{IT})$ this variable has a negative effect, however. The positive effect found in the first two steps could imply that simply choosing to transfer one's income to company $\mathrm{X}$ leads to a stronger relationship with this firm. Once a client has acquired a current account and a savings account at company $\mathrm{X}$, then the client is likely to be relatively loyal. This explains the absence of a positive effect in the model for the third step (SA $\rightarrow$ IT). The effect of Income_Transfer is, however, actually negative in this step of the acquisition pattern. The latter may be explained in terms of available assets. Clients who transfer a relatively low income to company $\mathrm{X}$ have the lowest probability of receiving a high income. That is to say, subjects who do not transfer any income to company $\mathrm{X}$ may transfer a high income elsewhere and, generally speaking, investment trust owners usually have a high income.
Such changes in the direction of effects justify application of the acquisition pattern approach. Other predictive modelling approaches fail to model such differences because they usually compare respondents to a mailing with nonrespondentss or compare owners of a product to clients who do not own the product of interest. ${ }^{21}$ Now if such a conventional approach were to be applied to, for example, acquisition of the investment trust a relatively weak model could be built. Acquisition of this product represents the third step in the acquisition pattern. This implies that two other steps in the acquisition pattern have already been taken by most investment trust owners, ie the acquisition of current accounts and the savings account. Table 2 shows that some variables have different effects (negative or positive) in different steps of the acquisition pattern. The latter implies that effects found in different stages cancel each other out when using the more conventional approach for building predictive models. In summary, an advantage of the acquisition pattern approach is that model development concentrates on the phase a consumer is in and only effects relevant for this particular phase are incorporated in the predictive model.

\section{DISCUSSION}

In this study an acquisition pattern was deduced from transactional data using ownership patterns. The found acquisition pattern was validated on the dates 
at which individual clients acquired products. The found acquisition pattern consists of the following products: current account, savings account, investment trust and securities.

Results of further analyses show that the found acquisition pattern is powerful and meaningful in terms of recognising cross-sell opportunities. Predictive power is high, because through the acquisition pattern approach one takes account of the relevance of developmental stages through which a client passes. This may not be the case when applying the conventional method for prospect selection, as discussed above. Moreover, the acquisition pattern approach is considered meaningful in the sense that linking propensities towards acquiring products to the developmental stages that clients go through enhances interpretation of the found effects. Such insight is important for marketing purposes as the formulation of strategies that appeal to the client depends on the understanding that marketers have with regard to their clients.

This approach may prove useful for more specific marketing purposes, such as predicting Life Time Value (LTV). ${ }^{22,23}$ That is to say, knowing whether a subject is more likely than others to acquire certain products gives insight into future revenues which subjects are likely to create. Thus, the acquisition pattern approach can also be used when calculating LTV. Further research could be directed at finding other practical applications of the introduced approach and of other variables influencing the passing of specific steps in the acquisition pattern reported in this paper.

\section{REFERENCES}

1 Felvey, J. (1982) 'Cross-selling by computer', Bank Marketing, July, pp. 2527.

2 Breur, T. and Paas, L. (2000) 'Building predictive models for direct-mail: A framework for choosing training and test data', Journal of Database Marketing, Vol. 8, No. 1, pp. 9-16.

3 Council on Financial Competition (1996) 'Present at the creation: Redefining competitive advantage through data-driven marketing and management', The Advisory Board Company, Washington DC.

4 Paroush, J. (1965) 'The order of acquisition of consumer durables', Econometrica, Vol. 33, pp. 225-235.

5 Kamakura, W. A., Ramaswami S. N. and Srivastave R. K. (1991) 'Applying latent trait analysis in the evaluation of prospects for cross-selling of financial services', International Journal of Research in Marketing, Vol. 8, pp. 329-349.

6 Paas, L. J. (1998) 'Mokken scaling characteristic sets and acquisition patterns of durable and financial products', Journal of Economic Psychology, Vol. 19, pp. 353-376.

7 Soutar, G. N. and Cornish-Ward, S. (1997) 'Ownership patterns for durable goods and financial assets: A Rasch analysis', Applied Economics, Vol. 29, pp. 903-911.

8 Kamakura et al. (1991) op. cit.

9 Paas, L. J. and Kuijlen, T. (1998) 
'Analysing generic needs through Mokken scaling and the Multi Nominal Logit Model', Journal of Targeting, Measurement and Analysis for Marketing, Vol. 7, No. 2, pp. 145-154.

10 Soutar and Cornish-Ward (1997) op. cit.

11 Madalla, G. S. (1983) 'Limiteddependent and qualitative data in econometrics', Cambridge University Press, Cambridge.

12 Amemiya, T. (1975) 'Qualitative models', Annals of Economic and Social Measurement, Vol. 4, pp. 363-372.

13 Blossfeld, H. P. and Rohwer, R. (1995) 'Techniques of event history modelling: New approaches to causal analysis', Lawrence Erlbaum Associates Publishers, New Jersey.

14 Mokken, R. J. and Lewis, C. (1982) 'A nonparametric approach to the analysis of binary item responses', Applied Psychological Measurement, Vol. 6, pp. 417-430.
15 Feick, L. F. (1987) 'Latent class models for analysis of behavioural hierarchies', Journal of Marketing Research, Vol. 24, pp. 174-186.

16 Kamakura et al. (1991) op. cit.

17 Paas (1998) op. cit.

18 Paas and Kuijlen (1998) op. cit.

19 Mokken and Lewis (1982) op. cit.

20 Satorra, A. and Saris, W. (1985) 'Power of the likelihood ratio test in covariance structure analysis', Psychometrika, Vol. 51, pp. 83-90.

21 Breur and Paas (2000) op. cit.

22 Hoekstra, J. C. and Huizingh, K. R. E. (1998) 'The lifetime value concept in customer-based marketing', Journal of Market-Focused Management, Vol. 3, pp. 257-274.

23 Jackson, D. R. (1994) 'Strategic application of customer lifetime value in the direct marketing environment', Journal of Targeting, Measurement and Analysis for Marketing, Vol. 3, pp. 9-17. 